\title{
Utilization of Palm Fiber King as a Strengthening Material on Biocomposite
}

\author{
G. A. Pohan ${ }^{l}$, T. Sugiarto ${ }^{\text {, D. D. G. Arianto }}{ }^{1}$ \\ ${ }^{1}$ Mechanical Engineering ,National Institute of Technology Malang \\ Email: gerard.pohan@gmail.com
}

\begin{abstract}
Royal palm (Roystonea regia) is still utilized in traditional way. In this study, royal palm fiber is employed as a reinforcing material in composites. The fiber is divided into two groups of fibers, which are continuous and discontinuous, with a length of fibers of 20 and $5 \mathrm{~cm}$, respectively. Continuous fibers are arranged in parallel, while discontinuous fibers are sown in random orientation. The variations in fiber volume fraction were $15,25,50$, and $75 \%$. Tensile tests were performed to determine composite strength. The test results show that composite tensile strength values with continuous fibers are higher than those of discontinuous fibers. In addition, the increase in fiber volume fraction is directly proportional to the tensile strength of the specimen. These results indicate that the royal palm fiber has the potential to be used in composite applications.
\end{abstract}

Keywords royal palm fiber, biocomposite, tensile strength

Paper type Research paper

\section{INTRODUCTION}

The royal palm plant that has the Latin name Roystonea regia still has not been fully utilized. It is still used traditionally. Plants originating from the Americas are often used as ornamental plants on the roadside (Naderali, et al., 2015). Seeds of the plants are used as animal feed (Naderali, et al., 2015). In addition, the leaves are processed into materials for traditional roofing houses (Glimn-Lacy, et al., 2006). Then, the wood is used for building materials (Connor, 2002). According to those facts, attempts to find other applications are necessary in order to increase usability and increase its economic value.

Composites are a type of material that is derived from a combination of two different types of materials. The composite consists of a material that acts as a matrix and filler. Matrix is a component that serves as a filler binder, therefore this component must have good adhesion. In addition, the matrix must have a good ductility nature. On the one hand, the filler is an element that gives strength to the composite. There are two forms of material used as fillers: particles form and fiber forms. Fiber-shaped fillers are more commonly used because they produce better composite strength. Fiberglass, carbon, and aramid are the kinds of materials that are widely used as synthetic fiber material. However, the use of synthetic materials is not environmentally friendly so scientists began researching about natural fibers to replace synthetic fibers.

Recently, several studies related to the utilization of natural fibers as a reinforcing material on composites or better known as biocomposites have been done. Research has been done using bamboo fiber (Lee, et al., 2006) (Chen, et al., 1998), ramie (Rouison, et al., 2006), linen (Liyan, et al., 2004), sisal (Joseph, et al., 1999), cotton (Tserki, et al., 2003), silk (Priya, et al., 2006), feathers (Huda, et al., 2009), and wool (Kelly, et al., 2011) as filler. However, opportunities of other natural fiber utilization are still open.

Previous study has shown that the royal palm fiber has several advantages (Rao, et al., 2007). The royal palm fiber has a light weight (density of $0.81 \mathrm{~g} / \mathrm{cm}^{3}$ ) and high tensile strength (tensile strength of $549 \mathrm{MPa}$ ). In addition, this plant is easy to find in tropical countries so easy to get it in Indonesia. Considering the advantages possessed by the royal palm fiber, this fiber is suitable if used as a filler material on composites in order to increase the value of the use.

\section{Experimental Method}


The material of specimen used for the research is royal palm's fiber and polyester resin which function as reinforcement and matrix, respectively. Royal palm fiber is cleaned prior to the specimen manufacturing to remove lignin that is able to reduce the adhesive power when mixed with resin. Subsequently, the fibers were cut using scissors and rulers resulting in two groups of fibers, continuous and discontinuous with lengths of $20 \mathrm{~cm}$ and $5 \mathrm{~cm}$, respectively. Then both types of fibers are arranged in a mold that has been smeared with wax to make it easier to remove specimens from the mold. The shape and dimensions of the specimens for the tests are shown in Figures 1 and Table 1. Each of these fiber types is arranged in different prints and with different ornaments. Continuous fibers are arranged in parallel, while discontinuous fibers are sown in random orientation. The resin which has been mixed with the catalyst is poured into the mold, then the surface of the resin is flattened. The mold is pressed using a press machine for 4 hours until the resin hardens. After that, the specimen is released from the mold. The variations in fiber volume fraction used were 15, 25, 50, and $75 \%$.

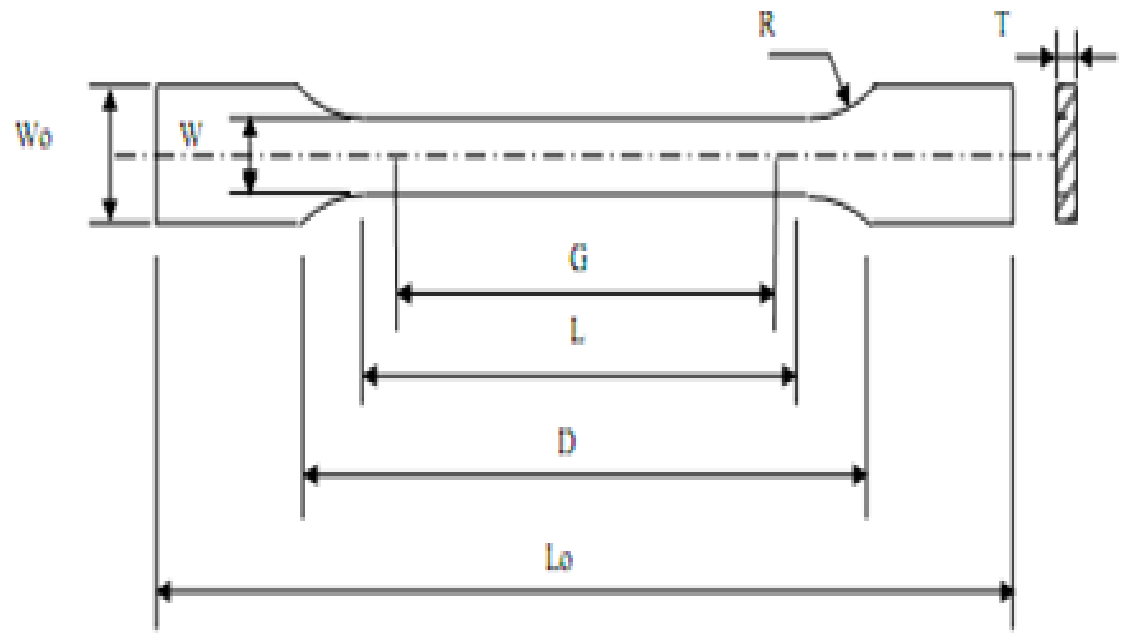

Figure 1. Illustration of ASTM D638 type 3 specimen for tensile test. (ASTM, 2008)

Table 1. Dimensions of ASTM D638 type 3 specimens for tensile test. (ASTM, 2008)

\begin{tabular}{ccccccccc}
\hline Dimension & W & G & D & Lo & R & Wo & L & T \\
\hline mm & 19 & 50 & 115 & 246 & 78 & 29 & 57 & 3.2 \\
\hline
\end{tabular}

After the specimen has been completed, a tensile test is performed to determine its strength. The specimen is placed on the holder of a Micro Computer Universal Testing Machine (Shimadzu, Japan) tensile test, then subjected to tensile load until fracture. The load data is recorded and used to calculate the tensile strength of the composite.

\section{Result}

Data of tensile strength of composites with continuous and discontinuous fibers is shown in Fig. 2. Based on these results, the value of specimen strength with continuous fibers has higher tensile strength compared to specimens with discontinuous fibers. In addition, fiber volume fraction also affects the tensile strength of specimens, either using continuous fibers or discontinuous fibers. The value of tensile strength of continuous and discontinuous fiber specimens with a volume fraction of $15 \%$ at 23.5 and $16.5 \mathrm{MPa}$ increased as the volume fraction increased to 28.4 and $22.3 \mathrm{MPa}$ at a $75 \%$ volume fraction. 


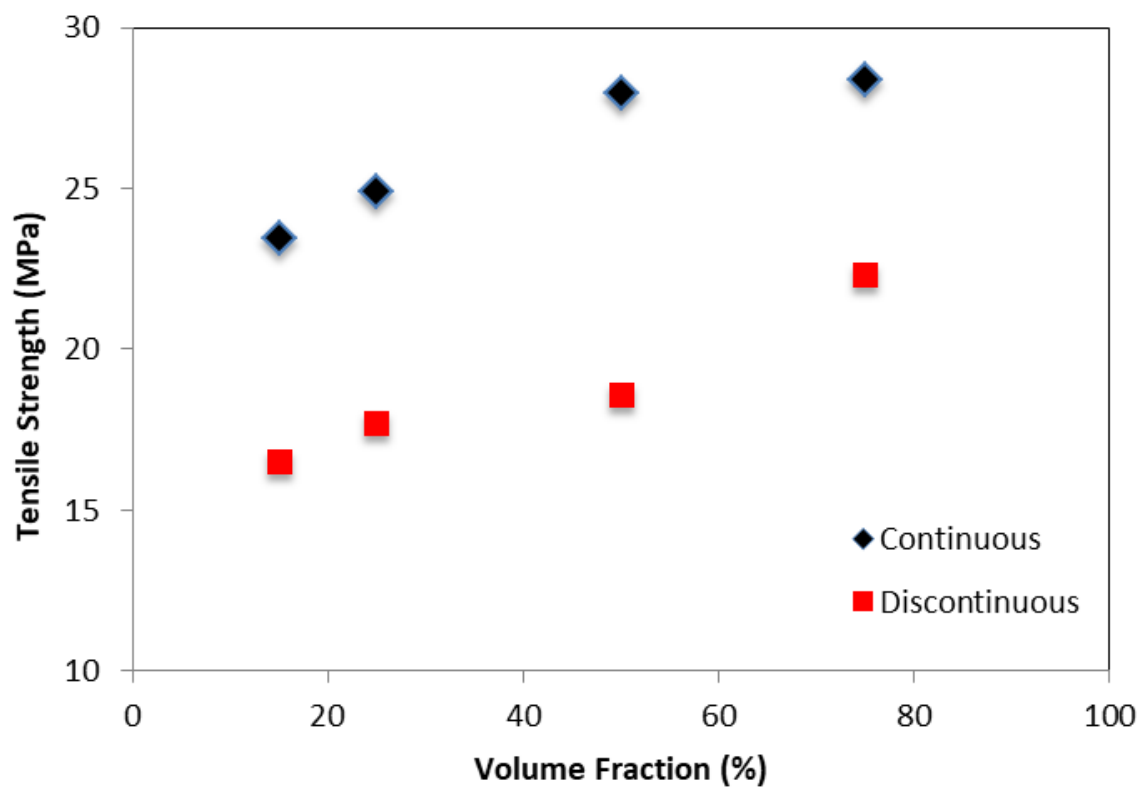

Figure 2. Tensile strength of the composites.

\section{Discussion}

a. Comparison of composite tensile strength with continuous and discontinuous fibers

Test results have shown that composites with continuous fibers show higher tensile strength than composites with discontinuous fibers. This is influenced by two things: fiber length and fiber orientation (Callister, 2011). Each explanation will be elaborated below.

The first factor affecting the composite tensile strength is the fiber length. This phenomenon can be explained by scheme at Fig. 3. In a composite with continuous fibers, where the fiber length $(l)$ is greater than the critical length $\left(l_{c}\right)$, the fiber is able to bear the tensile stress until it reaches the maximum tensile strength of the fiber $\left(\sigma^{*} f\right)$ as shown by Fig. 3a. In contrast, composites with discontinuous fibers will be damaged before the stress reaches the fiber tensile strength resulting in a decrease in composite strength (see Figure $3 b$ ).

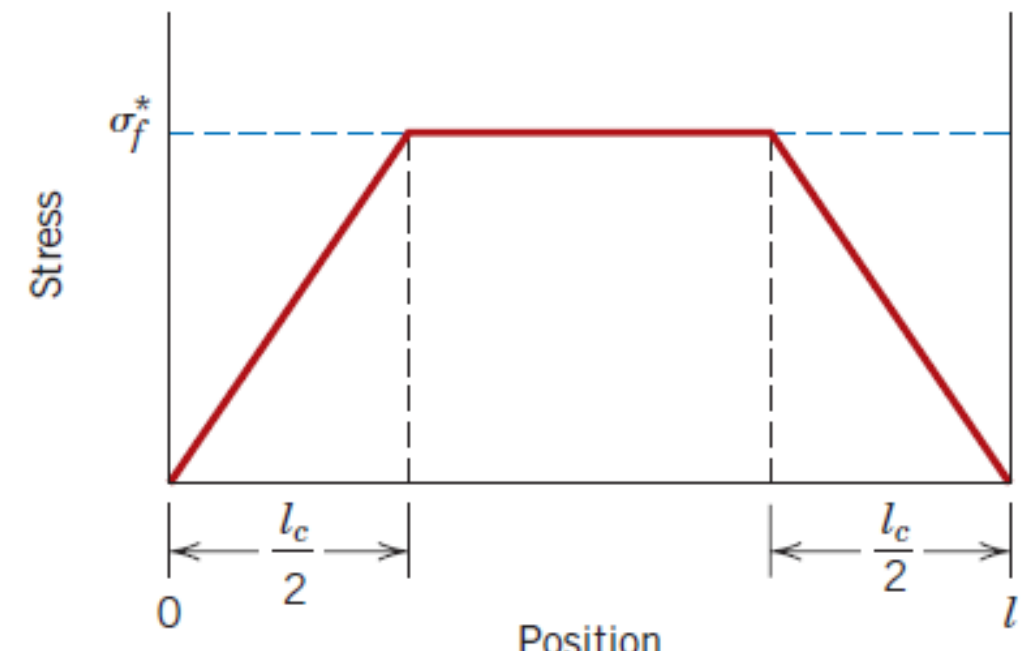

Position

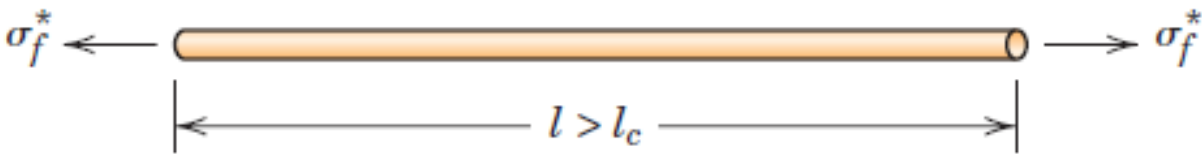


(a)

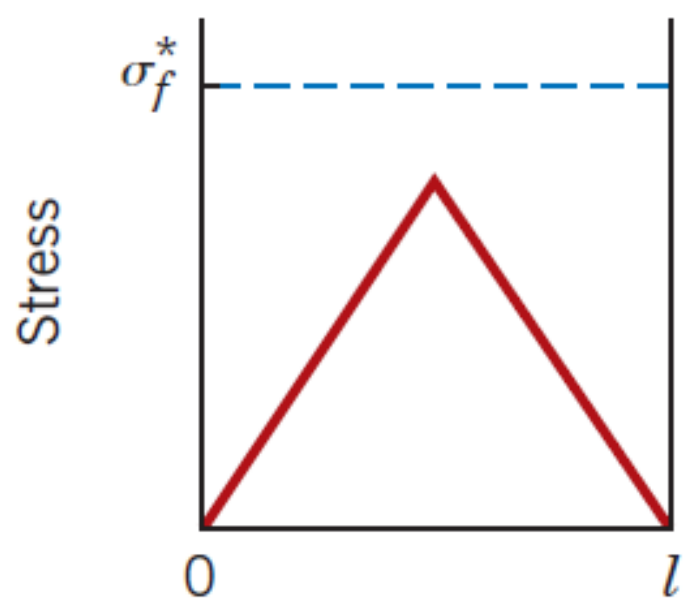

Position

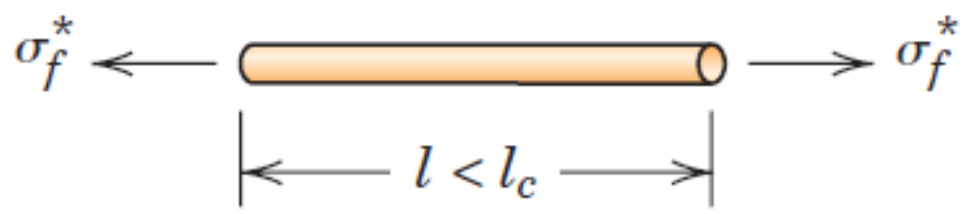

(b)

Figure 3. The stress-position profile of the composite with (a) continuous fibers and (b) discontinuous fibers. (Callister,

2011)

The second factor that affects composite strength is fiber orientation. Different fiber orientations will affect the value of the efficiency of composite reinforcement (see Table 2). Since tensile testing is carried out with one-way loads parallel to continuous fibers, the efficiency values of reinforcement in continuous fiber composites are higher than discontinuous fiber composites that have random fiber orientation so that their tensile strength is higher than that of discontinuous fiber composites.

Table 2. Reinforcement efficiency of fiber-reinforced composites for several fiber orientations and at various directions of stress application. (Callister, 2011)

\begin{tabular}{llc}
\multicolumn{1}{c}{ Fiber Orientation } & Stress Direction & $\begin{array}{c}\text { Reinforcement } \\
\text { Efficiency }\end{array}$ \\
\hline All fibers parallel & Parallel to fibers & 1 \\
\cline { 2 - 3 } & Perpendicular to fibers & 0 \\
\hline $\begin{array}{l}\text { Fibers randomly and uniformly distributed } \\
\text { within a specific plane }\end{array}$ & Any direction in the plane of the fibers & 0,375 \\
\hline $\begin{array}{l}\text { Fibers randomly and uniformly distributed } \\
\text { within three dimensions in space }\end{array}$ & Any direction & 0,2 \\
\hline
\end{tabular}


b. Effect of volume fraction on composite strength

According to the test results, fiber composition, both continuous and discontinuous fibers correlate to composite tensile strength. The relationship between fiber composition and composite strength is shown by equation (1) (Callister, 2011). The higher the fiber composition $\left(V_{f}\right)$, the higher the tensile strength $\left(\sigma_{c l}\right)$. Composite fibers are an important component because the fibers function to receive the load from the matrix when the force is applied to the composite. In addition, fiber also has a higher strength than matrix materials. The more fibers contained in the composite, the more the load is distributed to the fiber so that the composite will be stronger.

$\sigma_{c l}=\sigma_{m} V_{m}+\sigma_{f} V_{f}$

\section{Conclusion}

Based on the results of research that has been done, the conclusion that can be drawn is the royal palm fiber has the potential to be used in composite applications. To get the optimum result, it is neccesary to adjust the composition / fraction volume

\section{REFERENCES}

[1] ASTM D638 638-03: Standard Test Method for Tensile Properties of Plastics. [Book]. - [s.1.] : Current edition approved Apr, 2008. - Vol. 1.

[2] Callister W. D. Materials science and engineering [Book]. - New York : John Wiley \& Sons, 2011. - Vol. 5.

[3] Chen Xiaoya, Guo Qipeng and Mi Yongli Bamboo fiber-reinforced polypropylene composites: A study of the mechanical properties [Journal] // Journal of applied polymer science. - 1998. - pp. 1891-1899.

[4] Connor K. F. Roystonea regia (Kunth) O.F. [Book]. - Washington DC : USDA Forest Service Agriculture Handbook, 2002.

[5] Glimn-Lacy J. and Kaufman P. B. Palm Family (Arecaceae) [Book]. - Boston : Springer, 2006.

[6] Huda S. and \& Yang Y. Feather fiber reinforced light-weight composites with good acoustic properties [Journal] // Journal of Polymers and the Environment. - 2009. - p. 131.

[7] Joseph P. V., Joseph K. and Thomas S. Joseph, P. V., Joseph, K., \& Thomas, S. (1999). Effect of processing variables on the mechanical properties of sisal-fiber-reinforced polypropylene composites [Journal] // Composites Science and Technology. - 1999. - pp. 1625-1640.

[8] Kelly F. M. and \& Johnston J. H. Colored and functional silver nanoparticle- wool fiber composites [Journal] // ACS applied materials \& interfaces. - 2011. - pp. 1083-1092.

[9] Lee Seung-Hwan and Wang Siqun Biodegradable polymers/bamboo fiber biocomposite with bio-based coupling agent [Journal] // Composites Part A: Applied Science and Manufacturing. - 2006. - pp. 80-91.

[10] Liyan L. and Rui W. Linen Fibres-Reinforced Composites and Their Applications [J] [Journal] // Technical Textiles 2. - 2004. - pp. 37-40.

[11] Naderali N. [et al.] First Report of Phytoplasma (16SrI) Associated with Yellow Decline Disease of Royal Palms [Roystonea regia (Kunth) O. F. Cook] in Malaysia [Journal] // Journal of Phytopathology. - 2015. - pp. 1-5.

[12] Priya S. P. and \& Rai S. K. Studies on the mechanical performance of PMMA toughened epoxy-silk and PC toughened epoxy-silk fabric composites [Journal] // Journal of Reinforced Plastics And Composites. - 2006. - pp. 33-41.

[13] Rao K.M.M and Rao K.M. Extraction and Tensile Properties of Natural Fibers: Vakka, Date and Bamboo [Journal] // Composite Structures. 2007. - pp. 288-295.

[14] Rouison D., Sain M. and Couturier M. Resin transfer molding of hemp fiber composites: optimization of the process and mechanical properties of the materials [Journal] // Composite Science and Technology. - 2006. - pp. 895-906.

[15] Tserki V., Matzinos P. and \& Panayiotou C. Effect of compatibilization on the performance of biodegradable composites using cotton fiber waste as filler [Journal] // Journal of Applied Polymer Science. - 2003. - pp. 1825-1835. 